\title{
IS THERE SOMETHING SPECIAL ABOUT CARDIOVASCULAR ABNORMALITIES AND SUDDEN UNEXPECTED DEATH IN EPILEPSY AMONG PATIENTS WITH CHRONIC RENAL INSUFFICIENCY IN REGULAR HEMODIALYSIS PROGRAM?
}

\author{
Rui A. Gomes ${ }^{1,2}$, Silvana Kesrouani ${ }^{2}$, Jenner Cruz ${ }^{2}$, Alexandre L. Silva², Tânia M.G. Henriques², \\ Marly de Albuquerque , Ricardo M. Arida ${ }^{3}$, Eliza Y.F. Sonoda', Roberta M. Cysneiros ${ }^{4}$, \\ Vera C. Terra ${ }^{5}$, Carla A. Scorza', Esper A. Cavalheiro', Fulvio A. Scorza
}

\begin{abstract}
Of the many risk factors suggested for sudden unexpected death in epilepsy (SUDEP), higher frequency of seizures is a very consistent issue. Following this reasoning, it has been established that hemodialysis-associated seizure is a complication of dialysis procedure. Based on these facts, this study investigated a possible association between cardiovascular abnormalities and SUDEP among patients with chronic renal insufficiency in regular hemodialysis program. For that, a retrospective medical history of 209 patients was reviewed to investigate the occurrence of convulsive seizures and EKG abnormalities during dialytic program. Three patients presented generalized tonic-clonic seizures, one had partial seizure with secondary generalization, and one presented unclassified seizure. Any EKG abnormalities and SUDEP event were found in all patients evaluated. In conclusion, the present findings demonstrated uncommon the occurrence of seizures and also SUDEP. Probably, the main justification to not allow us to demonstrated a direct relation between SUDEP and cardiovascular diseases in hemodialysis are the reduced number of cases examined.
\end{abstract}

KEY WORDS: epilepsy, sudden death, heart, seizure, hemodialysis.

Existe algo de especial a respeito das anormalidades cardíacas e morte súbita e inesperada na epilepsia nos pacientes com insuficiência renal crônica no programa regular de hemodiálise?

\begin{abstract}
Resumo - Um dos principais fatores de risco para a morte súbita e inesperada na epilepsia (SUDEP) é a alta freqüência de crises epilépticas. Seguindo este raciocínio, tem sido estabelecido que as crises epilépticas associadas à hemodiálise seja uma complicação do procedimento dialítico. Baseado neste fato, este estudo investigou uma possivel associação entre anormalidades cardiovasculares e SUDEP nos pacientes com insuficiência renal crônica em um programa regular de hemodiálise. Para isto, um histórico médico retrospectivo de 209 pacientes foi revisado para avaliar a ocorrência de crises epilépticas e possíveis anormalidades no ECG durante o programa de diálise. Três pacientes apresentaram crises tônico-clonica generalizadas, um apresentou crise parcial com generalização secundária e um apresentou crise não-classificada. Não detectamos anormalidades no ECG e ocorrência de SUDEP em todos os pacientes avaliados. Em conclusão, na presente amostra constatou-se como rara a ocorrência de crises epilépticas e SUDEP. Provavelmente, o número reduzido de casos avaliados tenha sido responsável pela não observação de uma relação direta entre SUDEP e as doenças cardiovasculares na hemodiálise.
\end{abstract}

PALAVRAS-CHAVE: epilepsia, morte súbita, coração, crises epilépticas, hemodiálise.

\footnotetext{
'Disciplina de Neurologia Experimental, Universidade Federal de São Paulo/Escola Paulista de Medicina (UNIFESP/EPM), São Paulo SP, Brazil; ${ }^{2}$ Instituto de Nefrologia de Mogi das Cruzes, Mogi das Cruzes SP, Brasil; ${ }^{3}$ Departamento de Fisiologia, Universidade Federal de São Paulo/Escola Paulista de Medicina (UNIFESP/EPM), São Paulo SP, Brasil; ${ }^{4}$ Programa de Pós-Graduação em Distúrbio do Desenvolvimento da Universidade Mackenzie, São Paulo SP, Brasil; ${ }^{5}$ Departamento de Neurologia (Centro de Cirurgia das Epilepsias - CIREP), Faculdade de Medicina da Universidade de São Paulo, Ribeirão Preto SP, Brasil. Fundação de Amparo a Pesquisa do Estado de São Paulo (FAPESP), Cooperação Interinstitucional de Apoio a Pesquisa sobre o Cérebro (CInAPCe-FAPESP), and Conselho Nacional de Desenvolvimento Científico e Tecnológico (CNPq) supported this study.
}

Received 13 October 2008, received in final form 2 December 2008. Accepted 17 February 2009.

Dr. Fulvio Alexandre Scorza - Disciplina de Neurologia Experimental / Edificio Leal Prado - Rua Botucatu 862 - $04023-900$ São Paulo SP - Brasil. E-mail: scorza.nexp@epm.br 
Approximately epilepsy is the most common serious neurological condition and almost 50 million people worldwide have epilepsy ${ }^{1-3}$. The most common risk factors for epilepsy are cerebrovascular diseases, brain tumours, alcohol, traumatic head injuries, malformations of cortical development, genetic inheritance and infections of the central nervous system ${ }^{4}$. In resource-poor countries, endemic infections, such as malaria and neurocysticercosis seem to be major risk factors ${ }^{5}$. Actually, clinical data support that people with epilepsy are two- to three-fold increase to die prematurely than those without epilepsy and the most common epilepsy-related category of death is sudden unexpected death in epilepsy (SUDEP) ${ }^{6,7}$. Information concerning risk factors for SUDEP is conflicting, but potential risk factors include: age, early onset of epilepsy, duration of epilepsy, uncontrolled seizures, seizure frequency, seizure type, antiepileptic drugs number and winter temperatures ${ }^{6}$. Additionally, the underlying pathophysiology of SUDEP is unknown; however, it is very probable that cardiac arrhythmia play a potential role. In this way, Rugg-Gunn and collaborators ${ }^{8}$ using implantable loop recorders demonstrated that some patients with refractory partial epilepsy may have potentially life-threatening cardiac arrhythmias. Moreover, it has been established that repetitive seizures can alter the regulation of cardiac activity by the autonomic nervous system (ANS), and ANS dysregulation is thought to be associated with higher morbidity and mortality in patients with epilepsy'. In accordance with this reasoning, we postulated the question: is there a possible relation between epilepsy, renal dysfunction, cardiovascular abnormalities and hence SUDEP?

Cardiac disease is the major cause of death in patients with end-stage of renal disease, accounting for approximately $43 \%$ of all deaths ${ }^{10,11}$. In dialysis patients, about $20 \%$ of cardiac deaths are attributed to acute myocardial infarction, a catastrophic clinical event in this group of patients ${ }^{10,12}$. In parallel, it has been reported an estimated incidence of seizure of approximately $10 \%$ in patients with chronic renal failure ${ }^{13}$. In addition, Plum and Posner ${ }^{14}$ also noted that convulsions occurred in one third of patients with end-stage renal disease (ESRD) and was frequently a preterminal event. The seizures in these series usually were generalized tonic-clonic type; however, the mechanism of reduced seizure threshold in renal failure is still unknown. Hemodialysis-associated seizure (HAS) is a common complication of hemodialysis ${ }^{15}$. HAS occurs in $7 \%$ to $50 \%$ of children with ESRD, and their seizures are usually reported as generalized tonic-clonic seizures ${ }^{16}$. Risk factors for HAS include young age, prior history of seizures, malignant hypertension, microvascular diseases, uremic encephalopathy and cardiomyopathy. Moreover, induced brain water disequilibrium, hypocalcaemia, uremic toxins, the use of acetate in the dialysate, intracrani- al hemorrhage due to systemic heparinization, treatment with recombinant erythropoietin, hemodynamic and metabolic defects, and drugs such as penicillin and theophilline are also considered responsible for $\mathrm{HAS}^{16-18}$. If all these data are taken together, information on the management of seizures in renal failure should be disseminated among professionals treating systemic diseases. Based on these facts, we are interested here in exploring the occurrence of epilepsy and hence sudden unexpected death in patients with chronic renal insufficiency under regular hemodialysis program.

\section{METHOD}

A retrospective medical history of 209 patients was reviewed to investigate the occurrence epilepsy, cardiovascular abnormalities and hence sudden unexpected death in dialysis patients at the Nephrology Institute of Mogi das Cruzes. From 209 patients under dialytic treatment, 7 had suffered some type of convulsive seizure and were invited to participate in the study, but only 5 patients had agreed to participate. They were 4 males and 1 female, with a mean age of 42 years (range: 20 to 72 years old). The five patients have severe systemic arterial hypertension and were using antihypertensive drugs. In our clinic, all patients have monthly evaluation of total calcium and were receiving calcium carbonate $\left(\mathrm{CaCO}_{3}\right)$. The solution for the dialytic treatment contains $210.7 \mathrm{~g} / \mathrm{L}$ of $\mathrm{NaCl}$, with a calcium concentration of 2.5 or $3.5 \mathrm{mEq} / \mathrm{L}$.

All patients were evaluated for initial disease, duration, type and frequency of HAS and then submitted to clinical and neurological examination. The mean time of dialysis treatment and the electroencephalography (EEG) was analysed in all patients. The seizures were classified according the Commission on Classification and Terminology of International League Against Epilepsy ${ }^{19}$. The possible seizure triggering factors, such as the use or withdrawal of medications, sleep deprivation, arterial hypertension, infections, and electrolytic misbalance, especially hypocalcaemia, were also investigated.

EKG data for all patients was obtained from one or two EKG channels (used routinely at our center) utilizing two EKG electrodes. EKG electrodes were usually placed on the anterior chest, one on each side, though exact positioning was not standardized. EKG abnormalities were reviewed by a board certified physician (RAG, Director of the Nephrology Institute of Mogi das Cruzes). We would like to point out that part of the data used in the present study have already been published in a previous work developed by our research group ${ }^{20}$. The study received approval from the Human Research Ethics Committee, and all subjects signed an informed consent document.

\section{RESULTS}

In our study we analyzed the data of 5 out of 209 patients recruited under dialytic treatment at the Nephrology Institute of Mogi das Cruzes. All five patients had se- 
Table 1. Specific causes of end-stage of renal disease (Adapted by permission of the authors ${ }^{20}$ ).

\begin{tabular}{lccl}
\hline Patient & Age & Gender & Causes of end-stage of renal disease \\
\hline ADS & 23 & Female & Chronic glomerulonephritis \\
RDS & 20 & Male & Diabetic nephropathy \\
ORC & 45 & Male & Diabetic nephropathy \\
LCO & 43 & Male & Diabetic nephropathy \\
SAJ & 72 & Male & Diabetic nephropathy \\
\hline
\end{tabular}

vere systemic arterial hypertension and were using antihypertensive drugs. These patients were also using antiepileptic drug (phenytoin $200 \mathrm{mg} /$ daily) and $\mathrm{CaCO} 3(1.500$ $\mathrm{mg} /$ daily). The mean age of beginning of dialysis was 25 years. The mean duration of dialytic treatment was 5.8 years (range: 2 to 12 years). The causes of renal failure were diabetic nephropathy (4 patients) and chronic glomerolonephritis (1 patient) (Table 1). All patients had normal aluminum plasma levels and were not affected by other clinical pictures that could be led to possible aluminum intoxication. The signs of Chvostek and Trousseau were absent in all patients and the neurological examination was normal in 4 patients, but one presented pyramidal syndrome (left hemiparesia with pyramidal signs), with abnormal CT scan (hipodensity on right temporal lobe).

The seizure history of the five patients is listed on Table 2. Briefly, three patients presented generalized tonic-clonic seizures, one presented partial seizure with secondary generalization, and one presented unclassified seizure. All patients had seizures at home, two patients had seizures during dialysis procedure and one of them had presented convulsive status epilepticus. Two patients had already presented seizures prior the beginning of dialysis treatment; one of them without detectable structural CNS lesion, and the other showed hipodensity on right temporal lobe (vascular cerebral disease). All patients presented normal interictal EEG. At time of seizure, none of them presented infection, electrolytic misbalance (hypocalcemia), sleep deprivation, stress situation or were using pharmacological agents that lower the seizure threshold and can cause seizures, such as theophylline, antipsy- chotics and antidepressants. Any EKG abnormality and serious abnormalities were found in all patients evaluated by a board certified physician.

\section{DISCUSSION}

The primary aim of this study was to verify the possible association between epilepsy and hence sudden unexpected death in patients with chronic renal insufficiency under regular hemodialysis program. We note the cases evaluated ( 5 out of 209) that cardiovascular alterations and hence SUDEP is not a common event. Nevertheless, these findings need to be interpreted with caution. The study has methodological limitations; however, as research in this field must be guided by the potential for the prevention of SUDEP, a number of arguments might be put forward.

Firstly, it has long been believed that seizures are relatively a common complication of hemodialysis ${ }^{15}$. However, in our study we observed the occurrence of HAS in only $2 \%$ of our patients. In these lines, our results are not in agreement with previous studies, which related an estimated incidence of seizure of approximately $10 \%$ in patients with chronic renal failure ${ }^{13}$. Concerning the smaller occurrence of seizures in our patients and the no presence of SUDEP among them, we can pointed here that of the many risk factors suggested for SUDEP, higher frequency of seizures is a very consistent issue. Accordingly, among the rarely witnessed cases of SUDEP, the majority of patients proved to suffer a partial or generalized seizure immediately prior to death, suggesting a seizure-related cardiac or respiratory dysfunction ${ }^{21}$. Moreover, SUDEP is a rare event in patients in remission and only few such cases have been described ${ }^{22,23}$. In an elegant largest case-control study, Nilsson and colleagues demonstrated that seizure frequency is a strongest risk factor for SUDEP ${ }^{24}$. In their study, 57 SUDEP cases were included, of whom $91 \%$ had undergone necropsy. The relative risk of SUDEP increased with number of seizures per year and the estimated relative risk was $10.16(95 \% \mathrm{Cl} 2.94-35.18)$ in patients with more than 50 seizures per year, compared with those with up to two seizures per year.

With regard the second argument, in spite of reports

Table 2. Seizure history of the patients during regular hemodialysis program (Adapted by permission of the authors ${ }^{20}$ ).

\begin{tabular}{lcccc}
\hline Patient & $\begin{array}{c}\text { Seizures } \\
\text { (dialysis procedure) }\end{array}$ & $\begin{array}{c}\text { Seizures } \\
\text { (home) }\end{array}$ & Seizure's types & Seizure's frequency \\
\hline ADS & Yes & Yes & Unclassified & Five \\
RDS & Yes & Yes & Generalized tonic-clonic & Twice \\
ORC & No & Yes & Generalized tonic-clonic & Unique \\
LCO & No & Yes & Generalized tonic-clonic & Unique \\
SAJ & No & Yes & Partial with secondary generalization & Unique \\
\hline
\end{tabular}


that prior history of seizure did influence the risk of seizures among patients receiving hemodialysis ${ }^{16}$, we did not observe higher risk in our patients who had prior history of epilepsy. It is difficult to make comparisons between our with other studies since different factors may influence the analysis, such as the age of the subjects, type of seizures and risk factors for HAS as previously mentioned. In the same way and thinking about no presence of SUDEP in our study, it has been known that SUDEP appears to be an issue mainly in patients with chronic epilepsy ${ }^{22}$. We note in all cases evaluated (5 out of 209) that only two patients had already presented isolated seizures prior the beginning of dialysis treatment, not characterizing long duration of epilepsy in these cases. Our results are in agreement with previous studies that report a mean duration of the seizure disorder ranging from 15 to 20 years in SUDEP cases ${ }^{22}$.

Third, SUDEP is usually unwitnessed, but when witnessed, all studies that have identified the patients' seizure type report a history of primary or secondary generalized tonic-clonic seizures (GTCS) in at least $90 \%$ of SUDEP cases $^{22,25}$. Although three patients presented GTCS in our study, these seizures were isolated and no SUDEP cases were found. Following this reasoning, our results are totally in agreement with the elegant study of Birnbach and colleagues that comparing people with epilepsy who died with those who survived, described that majority of those who died had a history of GTSC and that the frequency of GTCS was greater in those who died ${ }^{26}$.

Finally, age is another interesting risk factor for SUDEP that could be explored in our study. The age of reported cases of SUDEP have ranged from 8 months to 83 years, however, the great majority of studies have been shown that mean ages of SUDEP range from 26 to 37 years ${ }^{21,22,25,27}$. In these lines, one explanation about the reason that we did not find SUDEP cases in our study is because the age of each patient evaluated by us is not related with the mean age of SUDEP occurrence. Moreover, it is important to note that some studies have found different decades of peak of incidence of SUDEP ${ }^{25}$ and although our study did not associated the relation between age and SUDEP, we could not make statements concerning the SUDEP risk factor related to age in our cases for epileptic population in general.

In conclusion, the results of present study are totally in agreement with our earlier research, demonstrating that seizures in renal failure continuous been considered an occasional event that does not usually become chronic $^{20}$. In this sense, we are sure that information on the management of seizures in renal failure and the possibility of SUDEP occurrence among patients with endstage of renal disease should be disseminated among professionals treating systemic diseases. In sum, we also believe that neurologist should be aware about cardiovas- cular abnormalities and hence SUDEP in patients with epilepsy receiving renal replacement therapy with dialysis and recommend these patients to be submitted to a cardiological investigation. Strategies, such as taking a detailed cardiovascular history, looking for cardiovascular disease, symptoms, cardiovascular risk factors and prior cardiac findings (electrocardiogram, echocardiogram and holter monitoring) should be developed by a cardiologist or a general practioner and assess if this could prevent SUDEP although this may require large populational studies ${ }^{28}$.

\section{REFERENCES}

1. Sander JW. The epidemiology of epilepsy revisited. Curr Opin Neurol 2003;16:165-170.

2. Sander JW. Some aspects of prognosis in the epilepsies: a review. Epilepsia 1993;34:1007-1016.

3. Kwan P, Sander JW. The natural history of epilepsy: an epidemiological view. J Neurol Neurosurg Psychiatry 2004;75:1376-1381.

4. Halatchev VN. Epidemiology of epilepsy: recent achievements and future. Folia Medica (Plovdiv) 2000;42:17-22.

5. Duncan JS, Sander JW, Sisodiya SM, Walker MC. Adult epilepsy. Lancet 2006;367:1087-1100.

6. Hitiris N, Mohanraj R, Norrie J, Brodie MJ. Mortality in epilepsy. Epilepsy Behav 2007;10:363-376.

7. Lhatoo SD, Sander JW. Cause-specific mortality in epilepsy. Epilepsia 2005;46:36-39.

8. Rugg-Gunn FJ, Simister RJ, Squirrell M, Holdright DR, Duncan JS. Cardiac arrhythmias in focal epilepsy: a prospective long-term study, Lancet 2004;364:2212-2219.

9. Harnod T, Yang CC, Hsin YL Shieh KR, Wang PJ, Kuo TB. Heart rate variability in children with refractory generalized epilepsy. Seizure 2008;17:297-301.

10. Herzog CA. Cardiac arrest in dialysis patients: taking a small step. Semin Dial 2004;17:184-185.

11. U.S. Renal Data System: USRDS Annual Data Report. Bethesda, MD: National Institutes of Health, National Institute of Diabetes and Digestive and Kidney Diseases 2003;74-98.

12. U.S. Renal Data System: USRDS Annual Data Report. Bethesda, MD: National Institutes of Health, National Institute of Diabetes and Digestive and Kidney Diseases 1999;89-100.

13. Bergen DC, Ristanovic R, Gorelick PB Kathpalia S. Seizures and renal failures. Internat J Artificial Organs 1994;17:247-251.

14. Plum F, Posner JB. Metabolic brain diseases causing coma. Contemp Neurol Ser 1972;10:1-286.

15. Sönmez F, Mir S, Tütüncüoglu S. Potential prophylatic use of benzodiazepines for hemodialysis-associated seizures. Pediatric Nephrology 2000;14:367-369.

16. Glenn CM, Astley SJ. Watkins SL. Dialysis associated seizures in children and adolescents. Pediatric Nephrology 1992;6:182-186.

17. Schwartz RD. Hemodialysis associated seizures. In: Nissensen AR, Fine RN (Eds). Dialysis therapy. Hanley Balfus: Philadelphia, 1993:88-90. 
18. Swash M, Rowan AJ. Electroencephalographic criteria of hypocalcemia and hypercalcemia. Arch Neurol 1972;26: 218-228.

19. Commission on classification and terminology of the international league against epilepsy. Proposal for revised clinical and electroencephalographic classification of epileptic seizures. Epilepsia 1981;22:489-501.

20. Scorza FA, Albuquerque M, Arida RM, et al. Seizure occurrence in patients with chronic renal insufficiency in regular hemodialysis program. Arq Neuropsiquiatr 2005;63:757-760.

21. Ryvlin P, Montavont A, Kahane P. Sudden unexpected death in epilepsy: from mechanisms to prevention. Curr Opin Neurol 2006;19:194-199.

22. Tomson T, Walczak T, Sillanpaa M, Sander JW. Sudden unexpected death in epilepsy: a review of incidence and risk factors. Epilepsia 2005;46:54-61.

23. Lhatoo SD, Langan Y, MacDonald BK, Zeidan S, Sander JW. Sudden unexpected death: a rare event in a large community based prospective cohort with newly diagnosed epilep- sy and high remission rates. J Neurol Neurosurg Psychiatry 1999;66:692-693.

24. Nilsson L, Farahmand BY, Persson PG, Thiblin I, Tomson T. Risk factors for sudden unexpected death in epilepsy: a casecontrol study. Lancet 1999;353:888-893.

25. Bell GS, Sander JW. Sudden unexpected death in epilepsy. Risk factors, possible mechanisms and prevention: a reappraisal. Acta Neurol Taiwan 2006;15:72-83.

26. Birnbach CD, Wilensky AJ, Dodrill CB. Predictors of early mortality and sudden death in epilepsy: a multidisciplinary approach. J Epilepsy 1991;4:11-17.

27. Stollberger C, Finsterer J. Cardiorespiratory findings in sudden unexplained/unexpected death in epilepsy (SUDEP). Epilepsy Res 2004;59:51-60.

28. Scorza FA, Arida RM, Cavalheiro EA. Cardiovascular abnormalities in patients with epilepsy receiving renal replacement therapy with dialysis: a true convergence of clinical cardiology, nephrology and neurology. Nephrol Dial Transplant 2008;23:1775-1776. 